\title{
Substantially increased sildenafil bioavailability after sublingual administration in children with congenital heart disease: two case reports
}

\author{
Alexandra Carls ${ }^{1}$, Julia Winter ${ }^{2}$, Yeliz Enderle ${ }^{1}$, Jürgen Burhenne ${ }^{1}$, Matthias Gorenflo ${ }^{2}$ and Walter E Haefeli ${ }^{*}$
}

\begin{abstract}
Introduction: Pulmonary hypertension is a progressive disease of diverse origin with devastating consequences in adults as well as in children. The phosphodiesterase 5 inhibitor sildenafil successfully lowers pulmonary vascular resistance. However, because of its poor enteral absorption, resulting in ineffective plasma concentrations, responses in infants and children are often erratic.
\end{abstract}

Case presentations: We report the cases of two Caucasian boys, one born at term (case 1) and one aged 2.5 years (case 2), who had structural cardiac and pulmonary defects accompanied by symptomatic pulmonary hypertension. They received sildenafil enterally and sublingually and also intravenously in one of them. Plasma samples were taken at various time points to determine the plasma concentrations of sildenafil and its partially active metabolite. Sildenafil and $N$-desmethyl sildenafil were quantified using a validated liquid chromatography/mass spectrometry method. Oxygen partial pressure was determined from routine arterial blood gas samples.

Conclusion: In agreement with previous observations in adults, we found that sublingual sildenafil was more extensively absorbed in our two pediatric patients. After sublingual administration, sildenafil plasma concentrations increased by $314 \%$ to $361 \%$ compared to enteral dosing. Concurrently, the metabolic ratio increased, suggesting not only that the overall absorption was enhanced but also that first-pass metabolism was partially bypassed. In case 2, the free fraction of sildenafil was $0.9 \%$, which is considerably less than in adults (4\%), suggesting that, in case 2, higher plasma concentration would have been needed to achieve effects similar to those in adults. Sublingual sildenafil appears to be a promising alternative route of administration in children with poor enteral absorption.

Keywords: Enteral, Plasma concentration, Pulmonary hypertension, Sildenafil, Sublingual

\section{Introduction}

The phosphodiesterase 5 (PDE5) inhibitor sildenafil lowers pulmonary vascular resistance in patients with pulmonary hypertension $(\mathrm{PH})$ [1]. Whereas enteral bioavailability in adults is about $40 \%$ [2], absorption in neonates and infants is often poor [3,4], thus limiting sildenafil's effectiveness [5]. In pediatric cases, intravenous administration effectively increases exposure [6] and vasodilator responses [5]. However, intravenous administration is not practicable for long-term maintenance therapies.

\footnotetext{
* Correspondence: WalterEmil.Haefeli@med.uni-heidelberg.de 'Department of Clinical Pharmacology and Pharmacoepidemiology, University of Heidelberg, Im Neuenheimer Feld 410, 69120 Heidelberg, Germany Full list of author information is available at the end of the article
}

In our present report, we describe the cases of two infants with poor enteral absorption of sildenafil. We observed that sublingual administration of sildenafil solution markedly increased exposure.

After obtaining written informed consent from the infants' parents for compassionate use of sildenafil, we collected venous blood samples to evaluate sildenafil exposure (molar metabolic ratios (MRs) of sildenafil/ $\mathrm{N}$-desmethyl sildenafil, estimated area under the plasma concentration-time curve (AUC) and thus relative sublingual bioavailability (F)). Sildenafil steady-state concentrations $\left(\mathrm{C}_{\mathrm{avg}, \mathrm{ss}}\right)$ were calculated by dividing AUC by the respective sampling period. Sildenafil, its partially active metabolite $N$-desmethyl-sildenafil and the free fraction (case 2) were quantified in plasma by using a validated liquid chromatography/mass spectrometry 
method (lower limit of quantification $1 \mathrm{ng} / \mathrm{ml}$ ) [7]. As a safety marker, we evaluated partial arterial oxygen pressure $\left(\mathrm{pO}_{2}\right)$. Statistical and pharmacokinetic analyses were carried out using Prism statistical software version 6.0 (GraphPad Software, San Diego, CA, USA).

\section{Case presentation 1}

A Caucasian boy born at term (birth weight $=3610 \mathrm{~g}$ ) became cyanotic 1 hour after birth. Despite continuous positive airway pressure (CPAP) support, his oxygen saturation continued to decrease, requiring the use of mechanical ventilation. Echocardiography revealed a persistent foramen ovale and an open ductus arteriosus Botalli with systolic right-to-left shunting. An open lung biopsy confirmed the suspected diagnosis of alveolar capillary dysplasia.

Because of the infant's worsening $\mathrm{pO}_{2}$ level, sildenafil treatment was started 6 weeks after birth with an enteral dose of $2 \mathrm{mg}$ four times daily via a nasogastric tube (using an in-house preparation according to a method described previously [8]), which was increased to $4 \mathrm{mg}$ four times daily 2 days later. Four weeks later, weaning from mechanical ventilation was initiated, supported by intermittent CPAP and nasal oxygen $\left(\mathrm{FiO}_{2}=35 \%\right.$ to $60 \%$, flow rate $=31 / \mathrm{min}$ to $41 / \mathrm{min}$ ). The patient's $\mathrm{pO}_{2}$ level was highly variable, ranging between $46 \mathrm{mmHg}$ and $102 \mathrm{mmHg}$ (mean $\pm \mathrm{SD}=70.9 \mathrm{mmHg} \pm 17.5 \mathrm{mmHg}$ ), suggesting that the sildenafil exposure was either variable or ineffective. Concurrently, the boy was also maintained on ambrisentan, midazolam, chloral hydrate, clonidine, teicoplanin, ceftazidime, levetiracetam, nystatin, ethacrynic acid, furosemide, spironolactone, metolazone, acetaminophen, levomethadone, colecalciferol, sodium fluoride, levothyroxine, acetylcysteine, salbutamol and omeprazole. He also received phenobarbital, a strong cytochrome P450 enzyme inducer that could possibly lower sildenafil exposure.

Plasma samples taken during three different dosing intervals of 2.75, 3.6 and 5 hours after dosing showed very low concentrations (Figure 1). Assuming that plasma concentrations were obtained during steady state, we combined these samples to estimate the AUC as a marker of drug exposure (Table 1).

We then switched sildenafil to sublingual doses administered with a small syringe ( $4 \mathrm{mg} / 2 \mathrm{ml}$ four times daily). Sildenafil plasma concentrations in blood samples taken after 4 weeks on this regimen were substantially higher (Figure 1) than those after enteral administration. $C_{a v g, s s}$ increased by $361 \%$ and $\mathrm{C}_{\mathrm{avg}, \mathrm{ss}}$ of $\mathrm{N}$-desmethyl sildenafil increased as well, albeit by only $35 \%$, resulting in an approximately threefold higher MR (Table 1). During sublingual sildenafil, mean $\mathrm{pO}_{2}$ was $85.9 \mathrm{mmHg}( \pm 27.2)$. By then, the patient was weaned from CPAP and received nasal oxygen $\left(\mathrm{FiO}_{2}=100 \%\right.$, flow $=0.5 \mathrm{l} / \mathrm{min}$ to $\left.11 / \mathrm{min}\right)$.
Nine days after being switched to sublingual sildenafil treatment, the boy was discharged from the hospital in an improved and stable respiratory condition, with sildenafil continued at home. No adverse drug reaction occurred during sildenafil administration.

\section{Case presentation 2}

Case 2 is that of a 2.5 -year-old boy (body weight $11 \mathrm{~kg}$ ) who had been treated with a hybrid approach (stenting of the ductus arteriosus and bilateral pulmonary artery banding) at the age of 6 weeks. Upon presentation to our hospital, he was diagnosed with atrial and ventricular septum defects, hypoplasia of the left ventricle, aortic isthmus stenosis, mitral valve insufficiency and persistent left superior vena cava. He underwent a Glenn procedure combined with Damus-Kaye-Stansel anastomosis to enlarge the systemic outflow tract, which resulted in a functional univentricular heart. Owing to low $\mathrm{pO}_{2}$, an additional $3.5 \mathrm{~mm}$ modified Blalock-Taussig shunt was built. After he was weaned from cardiopulmonary bypass, he developed severe hypoxia, was unresponsive to hyperventilation and inhaled nitric oxide. Therefore, continuous intravenous sildenafil was started $(0.088 \mathrm{mg} / \mathrm{kg} / \mathrm{h}$, approximately $23 \mathrm{mg} / \mathrm{d}$ ) and delivery was switched to sublingual administration $(8 \mathrm{mg} / 4 \mathrm{ml}$ four times daily), which was increased to $10 \mathrm{mg} / 5 \mathrm{ml}$ four times daily after 4 days. His clinical condition improved, and, 3 weeks later, sublingual administration was switched to enteral administration (10mg four times daily) via a nasogastric tube to facilitate administration of the large volume of the suspension. Concurrently, the child was also maintained on milrinone, dobutamine, metildigoxin, epinephrine, clonidine, neostigmine, furosemide, lisinopril, acetaminophen, levomethadone, simethicone, omeprazole, caspofungin and ceftazidime. He also received erythromycin and fluconazole, two strong cytochrome P450 enzyme inhibitors that can increase sildenafil concentrations, and metamizole, an enzyme-inducing drug that can potentially lower sildenafil exposure.

Three blood samples were taken during intravenous infusion and after sublingual and enteral administration (Figure 1). Routinely drawn arterial blood gas samples were collected, and the oxygenation values obtained on 3 consecutive days were averaged as a composite marker for safety.

The highest sildenafil plasma concentrations were achieved during intravenous administration (Figure 1 and Table 1). After sublingual administration, $\mathrm{C}_{\mathrm{avg}, \mathrm{ss}}$ increased by $314 \%$ compared to enteral administration. Concurrently, the AUC of $N$-desmethyl sildenafil decreased by $50 \%$, leading to an eightfold increase of the MR (Table 1). Compared to the bioavailability after intravenous administration, enterally delivered sildenafil bioavailability was $2.8 \%$ 


\section{Case 1}

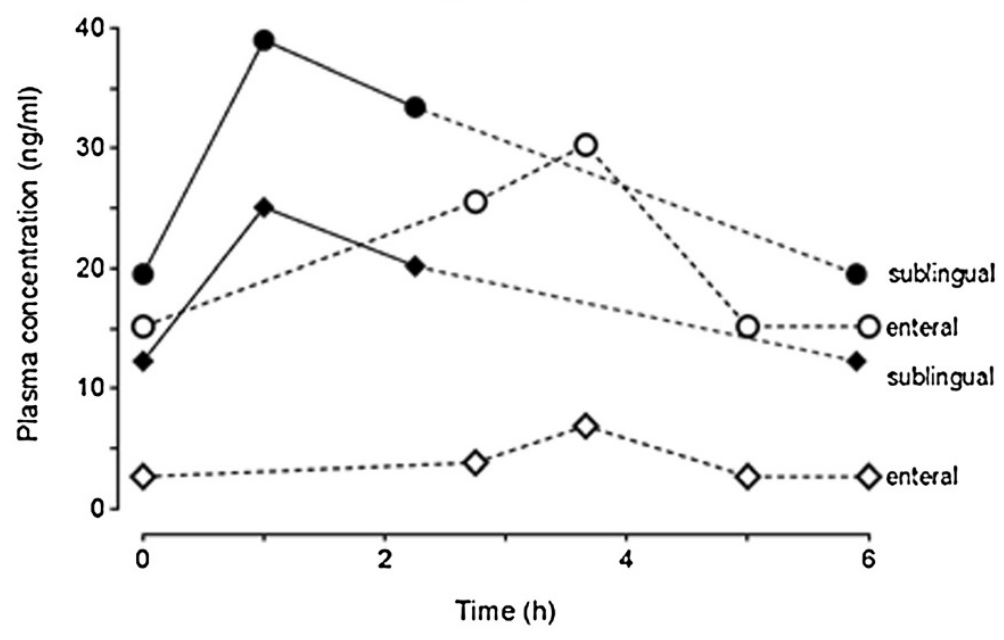

Case 2

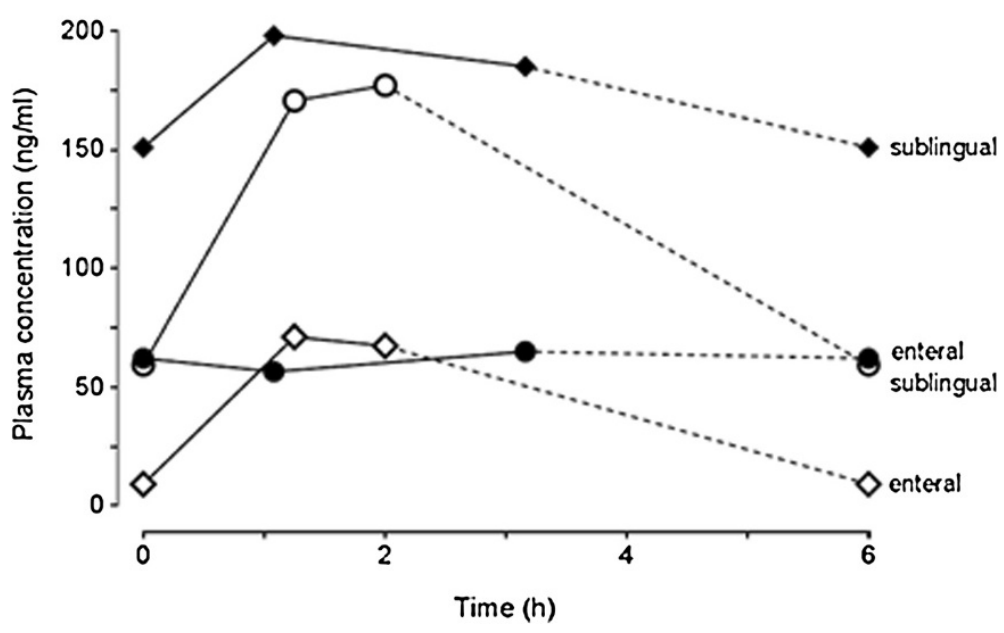

Figure 1 Graphs depicting plasma concentrations of sildenafil and $\mathbf{N}$-desmethyl sildenafil. Sildenafil (open diamonds) and its major, partially active metabolite $\mathrm{N}$-desmethyl sildenafil (circles) after enteral (open symbols) and sublingual administration (closed symbols) to two infants. The dotted lines are extrapolated assuming that plasma concentrations during steady state are identical at different dosing intervals.

and four times higher than after sublingual administration (Table 1). The unbound fraction of sildenafil was $0.9 \%$.

After extubation on the ninth postoperative day, oxygen was supplied via a high-flow nasal cannula (flow $=81 / \mathrm{min}$ to $12 \mathrm{l} / \mathrm{min}$, which could be reduced over time to $41 / \mathrm{min}$ ), which led to stable $\mathrm{pO}_{2}$ during sublingual $(38.8 \pm 4.05 \mathrm{mmHg})$ and enteral $(38.7 \pm 8.61 \mathrm{mmHg})$ sildenafil administration. Sildenafil was well-tolerated, and the patient was discharged from the hospital 28 days later, with enteral sildenafil continued at $10 \mathrm{mg}$ four times daily.

\section{Discussion}

In pediatric patients, congenital heart diseases, when combined with pulmonary vascular diseases, are frequently

Table 1 Pharmacokinetic parameters of sildenafil and $\mathbf{N}$-desmethyl sildenafil ${ }^{\mathbf{a}}$

\begin{tabular}{|c|c|c|c|c|c|c|c|c|c|c|c|c|}
\hline \multirow[t]{2}{*}{ Case } & \multicolumn{3}{|c|}{ Sildenafil $A U C_{0-6 h}((\mathrm{ng} / \mathrm{ml}) \times \mathrm{h})$} & \multicolumn{3}{|c|}{$\mathrm{N}$-desmethyl sildenafil $A U C_{0-6 h}((\mathrm{ng} / \mathrm{ml}) \times \mathrm{h})$} & \multicolumn{3}{|c|}{ MR } & \multicolumn{3}{|c|}{ Absolute bioavailability (\%) } \\
\hline & IV & Ent & SL & IV & Ent & SL & IV & Ent & SL & IV & Ent & SL \\
\hline 1 & - & 5.76 & 26.6 & - & 31.8 & 42.8 & - & 0.18 & 0.6 & - & - & - \\
\hline 2 & 919 & 25.5 & 106 & 70.4 & 74.7 & 37.2 & 12.7 & 0.33 & 2.78 & 100 & 2.78 & 11.6 \\
\hline
\end{tabular}

${ }^{\mathrm{a}} \mathrm{AUC}_{0-6 \mathrm{~h}}$, Estimated area under the concentration-time curve in a 6-hour dosing interval, normalized to dose; IV, Intravenous; Enteral; SL, Sublingual; MR, Metabolic sildenafil/ $\mathrm{N}$-desmethyl sildenafil ratio. 
accompanied by a large circulating blood volume, flooding the lungs through shunts and causing severe $\mathrm{PH}[1,6]$. In these children, intravenous sildenafil reduces pulmonary arterial pressure and shortens the time to extubation and the length of postoperative intensive care [6]. Barst and co-workers have recently shown dose-dependent hemodynamic effects of oral sildenafil in children with PH ( $n=235$, ages 1 to 17 years). Because there was no change in mortality over a 16 -week time period in their open-label extension study, their results revealed that children receiving the highest doses of sildenafil over 3 to 7 years had a higher mortality rate than those receiving medium or low doses of sildenafil (14\% and 9\% versus $20 \%$, respectively) [9]. As a consequence, the US Food and Drug Administration (FDA) issued a warning label against the use of sildenafil in children [10]. As subsequently pointed out by Abman and co-workers, however, withholding lower doses from children may not be appropriate. Because the observed risks that led to the FDA's issuing a warning label occurred only after several years of treatment, we did not consider the FDA warning label relevant for short-term use in patients such as ours [11]. When administered enterally, however, absorption is erratic. In almost half of these patients, sildenafil exposure is low and likely ineffective [3-5].

In adults with erectile dysfunction, sublingual sildenafil was at least equally effective as enteral sildenafil, and the onset of action after sublingual administration was more than 30 minutes faster than after enteral delivery [12]. In patients with end-stage heart failure, sublingual sildenafil decreases pulmonary pressure by approximately $20 \%$ [13]. Altogether, these results confirm rapid mucosal absorption. Sublingual pharmacokinetics have been assessed only in healthy volunteers, in whom bioavailability was found to be increased by roughly $50 \%$ compared to enteral administration [14].

In both children described in our present report, sublingual administration substantially increased sildenafil exposure. In case 2, absolute bioavailability could be estimated, and, though still low after sublingual administration (about 12\%), it was four times greater than after enteral administration. Compared to adults (bioavailability $=36 \%$ to $47 \%$ ) [2], enteral bioavailability in our pediatric patients was considerably lower, indicating that additional causes of impaired absorption may have been present. In adults, sildenafil absorption depends only minimally on gut content and food [2]; therefore, enteral feeding of our patients was not likely a cause of the limited enteral bioavailability observed.

After sublingual administration, the MR increased, suggesting not only that net absorption was enhanced but also that first-pass metabolism was partially bypassed. In healthy adults, the MR has been reported to be between 1.8 and 2.6 after enteral administration $[2,15,16]$. In the cases of comparable children described in previous publications, the MRs were 1.1 and 1.6 after enteral administration $[3,4]$ (that is, substantially larger than in our cases). These findings suggest extensive enteral or hepatic first-pass metabolism, which is unexpected in infants, who generally do not yet have fully developed oxidative metabolic capacity of the relevant cytochrome P450 isozyme CYP3A4 [17]. However, both children in our present report were maintained on enzyme-inducing agents (phenobarbital or metamizole [18]), probably partly explaining the differences in MR observed between sublingual and enteral administration. Because $N$-desmethyl sildenafil is a 2.5fold weaker PDE5 inhibitor than the parent compound [19], the net vasodilating effect is expected to increase with sublingual administration.

Sildenafil pharmacokinetics in severely ill neonates and infants are variable, and optimal target plasma concentrations are unknown. Indirect evidence suggests that total plasma concentrations greater than $100 \mathrm{ng} / \mathrm{ml}$ in adults are needed for effectiveness [20]. Sildenafil is highly bound to albumin and $\alpha_{1}$-acid glycoprotein (96\%) in adults (4\% free fraction), and binding depends on age. In young males, the unbound fraction was reported to be $26 \%$ higher than in elderly individuals [16]. In our second case, the free fraction was high enough to be quantified and was surprisingly low $(0.9 \%)$. If the concentration-response curve is similar across all age ranges, then it appears possible that, to achieve optimal effects, infants will require higher total plasma concentrations than adults.

Besides the fact that information in case reports is limited in general, another limitation is worth mentioning. We collected few blood samples, and the estimated enteral AUC value in the first case was composed of samples collected in three consecutive dosing intervals. Although this strategy confirmed that the exposure with sildenafil was consistently low, it assumed that pharmacokinetic variability between doses is small, which is unknown in this population. Finally, our findings suggest that sublingual sildenafil may become a promising route of administration in pediatric patients. However, its use cannot be broadly recommended before thorough pharmacokinetic data are available. In addition, a formulation with a higher sildenafil concentration probably also should be developed, because the sublingual volumes may become large if high sildenafil doses are to be administered.

\section{Conclusion}

Switching from enteral to sublingual administration in two infants with poor enteral absorption of the drug substantially increased sildenafil exposure and favorably shifted the MR toward higher concentrations of the more active parent compound. These findings suggest that the sublingual route of administration may be a 
promising way to increase sildenafil exposure in the many pediatric patients with poor enteral availability.

\section{Consent}

Written informed consent was obtained from both patients' parents for publication of this case report and any accompanying images. A copy of the written consent is available for review by the Editor-in-Chief of this journal.

\section{Abbreviations}

AUC: Plasma concentration time curve; $C_{\text {avg,ss: }}$ Steady-state concentration; CPAP: Continuous positive airway pressure; $\mathrm{FiO}_{2}$ : Fraction of inspired oxygen; FDA: US Food and Drug Administration; MR: Molar metabolic ratio; PH: Pulmonary hypertension; PDE5: Phosphodiesterase $5 ; \mathrm{PO}_{2}$ : Partial arterial oxygen pressure.

\section{Competing interests}

The authors declare that they have no competing interests.

\section{Authors' contributions}

AC, WEH and MG made substantial contributions to the conception of sublingual administration of the drug to achieve higher systemic availability. AC, JW, MG and WEH acquired, calculated and interpreted the data and related pharmacology to clinical outcome. YE and JB were responsible for the biochemical analysis of the blood samples. AC and WEH were the major contributors to the writing of the manuscript. JW, YE, JB and MG were involved in drafting parts of the manuscript and revising it critically for clinical and pharmacological content. All authors read and approved the final manuscript.

\section{Acknowledgement}

We thank Monika Maurer and Magdalena Longo for excellent technical assistance. We acknowledge the financial support of the German Research Foundation (DFG, Deutsche Forschungsgemeinschaft) and Ruprecht-KarlsUniversity Heidelberg within the funding programme Open Access Publishing.

\section{Author details}

${ }^{1}$ Department of Clinical Pharmacology and Pharmacoepidemiology, University of Heidelberg, Im Neuenheimer Feld 410, 69120 Heidelberg, Germany. ${ }^{2}$ Department of Pediatric Cardiology and Congenital Heart Diseases, University of Heidelberg, Im Neuenheimer Feld 430, 69120 Heidelberg, Germany.

Received: 11 December 2013 Accepted: 17 March 2014 Published: 30 May 2014

\section{References}

1. Wardle AJ, Tulloh RM: Paediatric pulmonary hypertension and sildenafil: current practice and controversies. Arch Dis Child Educ Pract Ed 2013, 98:141-147.

2. Nichols DJ, Muirhead GJ, Harness JA: Pharmacokinetics of sildenafil after single oral doses in healthy male subjects: absolute bioavailability, food effects and dose proportionality. Br J Clin Pharmacol 2002, 53(Suppl 1):5S-12S.

3. Ahsman MJ, Witjes BC, Wildschut ED, Sluiter I, Vulto AG, Tibboel D, Mathot RA: Sildenafil exposure in neonates with pulmonary hypertension after administration via a nasogastric tube. Arch Dis Child Fetal Neonatal Ed 2010, 95:F109-F114.

4. Apitz C, Reyes JT, Holtby H, Humpl T, Redington AN: Pharmacokinetic and hemodynamic responses to oral sildenafil during invasive testing in children with pulmonary hypertension. J Am Coll Cardiol 2010, 55:1456-1462.

5. Lammers AE, Haworth SG, Pierce CM: Intravenous sildenafil as an effective treatment of pulmonary hypertensive crises during acute intestinal malabsorption. Cardiol Young 2006, 16:84-86.

6. Fraisse A, Butrous G, Taylor MB, Oakes M, Dilleen M, Wessel DL: Intravenous sildenafil for postoperative pulmonary hypertension in children with congenital heart disease. Intensive Care Med 2011, 37:502-509.

7. Yin J, Kukucka M, Hoffmann J, Sterner-Kock A, Burhenne J, Haefeli WE, Kuppe $H$, Kuebler WM: Sildenafil preserves lung endothelial function and prevents pulmonary vascular remodeling in a rat model of diastolic heart failure. Circ Heart Fail 2011, 4:198-206.
8. Nahata MC, Morosco RS, Brady MT: Extemporaneous sildenafil citrate oral suspensions for the treatment of pulmonary hypertension in children. Am J Health Syst Pharm 2006, 63:254-257.

9. Barst RJ, Ivy DD, Gaitan G, Szatmari A, Rudzinski A, Garcia AE, Sastry BK Pulido T, Layton GR, Serdarevic-Pehar M, Wessel DL: A randomized, double-blind, placebo-controlled, dose-ranging study of oral sildenafil citrate in treatment-naive children with pulmonary arterial hypertension. Circulation 2012, 125:324-334.

10. US Food and Drug Administration: FDA Drug Safety Communication: FDA recommends against use of Revatio (sildenafil) in children with pulmonary hypertension. Silver Spring, MD: FDA; 2012. Available at http://www.fda.gov/ drugs/drugsafety/ucm317123.htm (accessed 25 March 2014).

11. Abman SH, Kinsella JP, Rosenzweig EB, Krishnan U, Kulik T, Mullen M, Wesse DL, Steinhorn R, Adatia I, Hanna B, Feinstein J, Fineman J, Raj U, Humpl T, Pediatric Pulmonary Hypertension Network (PPHNet): Implications of the U.S. Food and Drug Administration warning against the use of sildenafil for the treatment of pediatric pulmonary hypertension. Am J Respir Crit Care Med 2013, 187:572-575.

12. De Siati M, Saugo M, Franzolin N: The start of pharmacological activity after sublingual administration of sildenafil citrate in 30 patients affected by erectile dysfunction. Arch Ital Urol Androl 2003, 75:18-20.

13. Freitas AF Jr, Bacal F, Oliveira JL Jr, Santos RHB, Moreira LFP, Silva CR, Mangini S, Carneiro RMD, Fiorelli Al, Bocchi EA: [Impact of sublingual sildenafil on pulmonary hypertension in patients with heart failure] [in English Portuguese and Spanish]. Arq Bras Cardiol 2009, 92:116-126.

14. Zayed R, Kamel AO, Shukr M, El-Shamy A: An in vitro and in vivo comparative study of directly compressed solid dispersions and freeze dried sildenafil citrate sublingual tablets for management of pulmonary arterial hypertension. Acta Pharm 2012, 62:411-432.

15. Muirhead GJ, Wulff MB, Fielding A, Kleinermans D, Buss N: Pharmacokinetic interactions between sildenafil and saquinavir/ritonavir. Br J Clin Pharmacol 2000, 50:99-107.

16. Muirhead GJ, Wilner K, Colburn W, Haug-Pihale G, Rouviex B: The effects of age and renal and hepatic impairment on the pharmacokinetics of sildenafil. Br J Clin Pharmacol 2002, 53(Suppl 1):21S-30S.

17. de Wildt SN: Profound changes in drug metabolism enzymes and possible effects on drug therapy in neonates and children. Expert Opin Drug Metab Toxicol 2011, 7:935-948.

18. Saussele T, Burk O, Blievernicht JK, Klein K, Nussler A, Nussler N, Hengstler JG, Eichelbaum M, Schwab M, Zanger UM: Selective induction of human hepatic cytochromes P450 2B6 and 3A4 by metamizole. Clin Pharmacol Ther 2007, 82:265-274.

19. Hyland R, Roe EG, Jones BC, Smith DA: Identification of the cytochrome P450 enzymes involved in the $\mathrm{N}$-demethylation of sildenafil. $\mathrm{Br} J \mathrm{Clin}$ Pharmacol 2001, 51:239-248.

20. Karatza AA, Bush A, Magee AG: Safety and efficacy of sildenafil therapy in children with pulmonary hypertension. Int J Cardiol 2005, 100:267-273.

\section{doi:10.1186/1752-1947-8-171}

Cite this article as: Carls et al:: Substantially increased sildenafil bioavailability after sublingual administration in children with congenital heart disease: two case reports. Journal of Medical Case Reports 2014 8:171.

\section{Submit your next manuscript to BioMed Central and take full advantage of:}

- Convenient online submission

- Thorough peer review

- No space constraints or color figure charges

- Immediate publication on acceptance

- Inclusion in PubMed, CAS, Scopus and Google Scholar

- Research which is freely available for redistribution 